\title{
Experimental research on the machinability of Hardox steel by abrasive waterjet cutting
}

\author{
Alexandru Catalin Filip ${ }^{1,}{ }^{,}$, Mircea Anton Vasiloni ${ }^{1}$, and Laurentiu Aurel Mihail ${ }^{1}$ \\ ${ }^{1}$ Transilvania University of Brasov, Department of Manufacturing Engineering, Mihai Viteazul No.5, \\ Romania
}

\begin{abstract}
One of the main present industry challenges is finding the most efficient manufacturing process for a certain part. When parts are made of strong steels like Hardox, their fabrication method is usually difficult. Abrasive waterjet cutting (AWJ) is one of the cutting processes which can be used in this case. This paper presents an experimental research on the machinability of Hardox steel by AWJ. The experiments were conducted using a factorial design model considering two of the main influence parameters like the traverse speed and the distance between the nozzle and the surface of the material. Based on the measurement of the dimensions and the roughness of the parts, the influence of the parameters was revealed and analyzed. The manufacturing time was also compared, as it directly influences the production cost. Further research is considered to develop a mathematical model which can be used for a proper choice of the process parameters depending on the initial requirements.
\end{abstract}

\section{Introduction}

The equipment used in heavy industries like mining or the construction of roads must meet special requirements such as a strong wear resistance and a high tenacity, leading to a good strength-to-weight ratio. Hardox steel alloys $[1,2]$ are some of the recent used in the field. Such steels are usually difficult to process by traditional mechanical cutting processes because of their poor machinability by cutting. In this case, a method like abrasive waterjet cutting (AWJ) can be applied.

Abrasive waterjet machining is a flexible manufacturing process. It is based [3, 4], Figure 1a, on using a high pressure waterjet (1) guided through a small calibrated orifice (2) and mixed with fine abrasive particles in a mixing chamber (3). The abrasive jet is then sent through a nozzle (10), towards the surface of the material. The high speed of the abrasive jet creates enough force able to cut the material of the part. The main advantages of the method are the capacity to cut almost any type of material, no thermal influence, easy and fast setup and a high flexibility. The process is also environmentally friendly as the "tools" - water and abrasive particles - are fully recyclable.

However, the method has some limitations. The main one is the kerf geometry which depends on the machine dynamics. If the machine does not have kerf compensation options

\footnotetext{
*Corresponding author: filipal@,unitbv.ro
} 


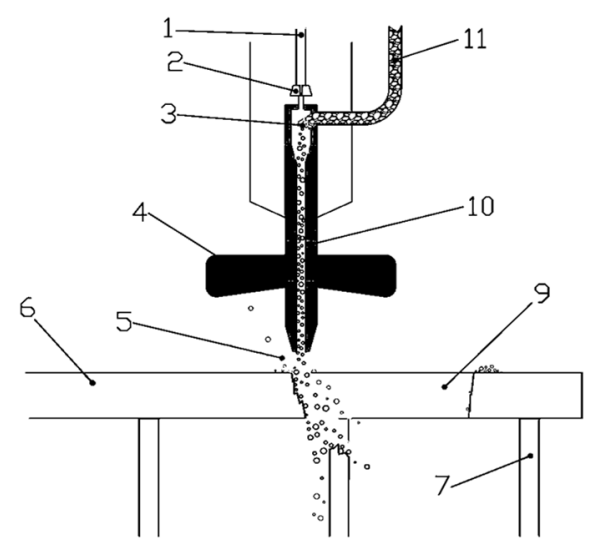

a.

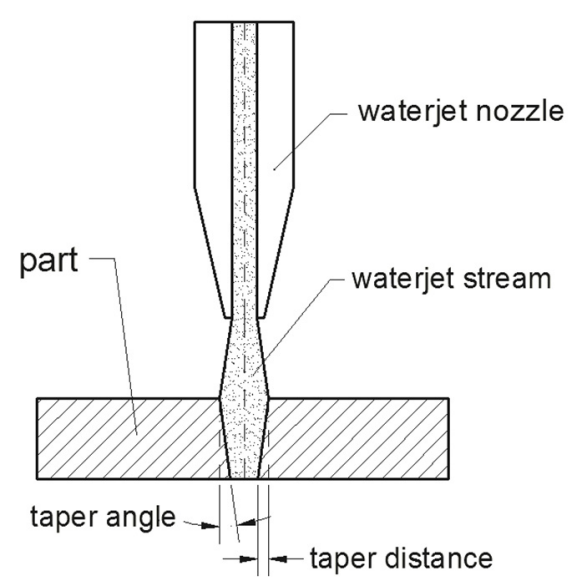

b.

Fig. 1. a. Principle of abrasive waterjet cutting; b. Taper kerf formation.

then the kerf will be tapered, Figure 1b, and also the surface of the part will have geometry deviations due to this phenomenon.

One other issue is the model to be used on a new material. Some mathematical models have been studied and developed in the last decade [5-7]. Each of them has a specific range of validity or was developed for a certain type of material. Usually, each abrasive waterjet machine uses its own cutting model and it has a materials database from which the operator can select the one needed. If the material is not in that database, there will have to be selected a similar one, but the cutting model will not be accurate and the results may not be as expected.

Since for the Hardox steels no technological data was found for the abrasive machining method, this paper presents an experimental study on the AWJ of this material aiming to reveal the proper set of values for the process parameters depending on the quality of the cut.

\section{Run of experiments and measurement of the parts}

The experiments were realized in the laboratory of Advanced Manufacturing Technologies, on a waterjet machine type Maxiem, having a $20 \mathrm{HP}$ pump and a maximum water pressure of 3500 bar. The dynamics of the machine does not have the possibility of automatic tilting, to compensate the effect of taper surface. The abrasive feeding system is a regular one, with constant feed rate, which was carefully measured before the experiments.

The material of the parts is steel Hardox $400[1,2]$ which has the mechanical properties according to Table 1.

Table 1.Mechanical properties of the steel Hardox 400.

\begin{tabular}{|c|c|c|c|}
\hline $\begin{array}{c}\text { Hardness HBW } \\
\text { Brinell }\end{array}$ & $\begin{array}{c}\text { Yield Strength } \\
{[\mathbf{M P a}]}\end{array}$ & $\begin{array}{c}\text { Tensile Strength } \\
{[\mathbf{M P a}]}\end{array}$ & Elongation [\%] \\
\hline $370 \ldots 430$ & 1000 & 1250 & $10 \%$ \\
\hline
\end{tabular}

The cutting was performed on a plate made of Hardox 400 having the thickness of 20 $\mathrm{mm}$. The design of the parts is presented in Figure $2 \mathrm{a}$. Some manufactured parts can be seen in Figure $2 b$. 

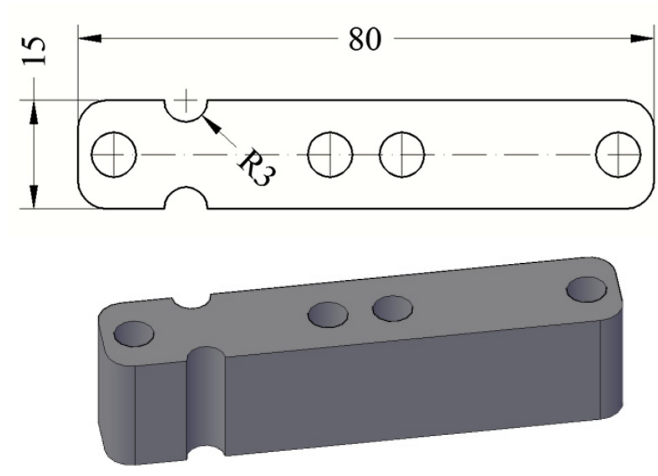

a.

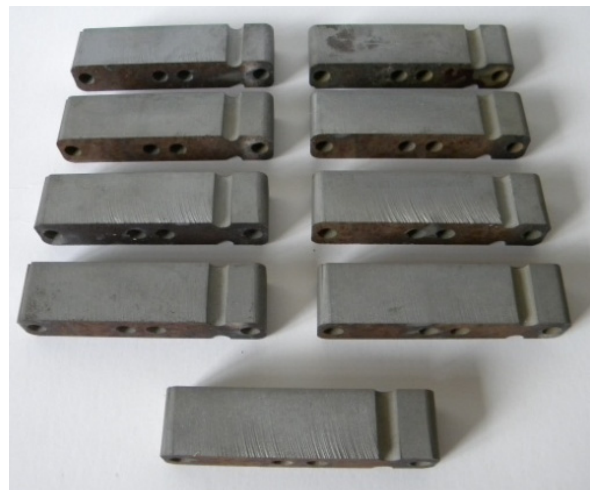

b.

Fig. 2. a. Design of the manufactured part; b. Sample parts cut with AWJ during the tests.

The main parameters of influence which are considered by the comprehensive researches until present day [3-9] are the water pressure, the traverse speed, the abrasive flow rate and the standoff distance between the nozzle and the surface of the material to be cut. As the water pressure directly influences the process productivity and costs, almost all researches agree that it is better to use the maximum values given by the equipment. For similar reasons, there was used the default abrasive flow rate given by the equipment. The values of these last two and other constant parameters are given in Table 2.

Table 2.Values of the constant parameters used during the tests.

\begin{tabular}{|c|c|c|c|c|}
\hline $\begin{array}{c}\text { Water pressure } \\
\text { [bar] }\end{array}$ & $\begin{array}{c}\text { Abrasive flow } \\
\text { rate [g/min] }\end{array}$ & Abrasive type & $\begin{array}{c}\text { Jewel orifice } \\
\text { diameter [mm] }\end{array}$ & $\begin{array}{c}\text { Nozzle orifice } \\
\text { diameter } \\
{[\mathbf{m m}]}\end{array}$ \\
\hline 3500 & 370 & garnet $80 \mathrm{mesh}$ & 0.279 & 0.838 \\
\hline
\end{tabular}

The two variable process parameters considered were the traverse speed (TRS) and the standoff distance (STD). Their range of values was established either by studying experiments done by others [9-11], either by some preliminary tests done by the authors.

Since one aim of this research is to find the proper machinability number to be used for steel Hardox 400 on Maxiem/Omax type AWJ machines, there were selected two limits for this number, 60 and 95 . The machine software requires also a certain number for the quality of the cut, between five values, numbered from 1 to 5 . Depending on the values of the machinability and the quality of the cut result the values of the traverse speed.

The experiments were conducted by a design plan using a factorial design based on three parameters - the machinability number, the quality of the cut and the standoff distance - and two limits of values for them. The middle range values combination was also included. Therefore, there were necessary 9 experiments into a set. Their values are shown in Table 3.

The resulting traverse speed from Table 3 is the linear speed used during the experiments, thus it is the cutting speed along the straight lines of the part.

In Table 3 there is also mentioned the cutting time, as it was calculated by the machine software.

After the trials each part was analyzed in terms of dimensional accuracy and the surface quality. Measurements were made along the two linear faces of each part.

The dimensional accuracy and the taper effect were analyzed by measuring the width of the parts in the middle of the length, Figure 3, on the two sides, named the upper and the 
bottom. The upper side is the entrance side of the waterjet and the bottom side is the exit side of the waterjet. The surface quality was analyzed by measuring the roughness with a portable tester Mitutoyo SJ210 Surftest, on the two linear faces of each part, approximately at $5 \mathrm{~mm}$ from the edge, both on the upper side and the bottom one, as shown in fig. 5 . The mean values were calculated for each measurement.

Table 3.Values of the variable parameters used during the tests.

\begin{tabular}{|c|c|c|c|c|c|}
\hline $\begin{array}{c}\text { Trial } \\
\text { Nr. }\end{array}$ & $\begin{array}{c}\text { Machinability } \\
\text { Number }\end{array}$ & $\begin{array}{c}\text { Quality of } \\
\text { Cut }\end{array}$ & $\begin{array}{c}\text { Standoff } \\
\text { Distance } \\
{[\mathbf{m m}]}\end{array}$ & $\begin{array}{c}\text { Resulting } \\
\text { Traverse Speed } \\
{[\mathbf{m m} / \mathbf{m i n}]}\end{array}$ & $\begin{array}{c}\text { Cutting } \\
\text { Time } \\
{[\mathbf{m i n}]}\end{array}$ \\
\hline 1 & 60 & 2 & 1.5 & 63.18 & 13.73 \\
\hline 2 & 60 & 4 & 1.5 & 28.48 & 22.58 \\
\hline 3 & 95 & 2 & 1.5 & 100.03 & 8.33 \\
\hline 4 & 95 & 4 & 1.5 & 45.07 & 13.63 \\
\hline 5 & 60 & 2 & 2.5 & 63.18 & 13.73 \\
\hline 6 & 60 & 4 & 2.5 & 28.48 & 22.58 \\
\hline 7 & 95 & 2 & 2.5 & 100.03 & 8.33 \\
\hline 8 & 95 & 4 & 2.5 & 45.07 & 13.63 \\
\hline 9 & 77.5 & 3 & 2 & 51.2 & 12.21 \\
\hline
\end{tabular}

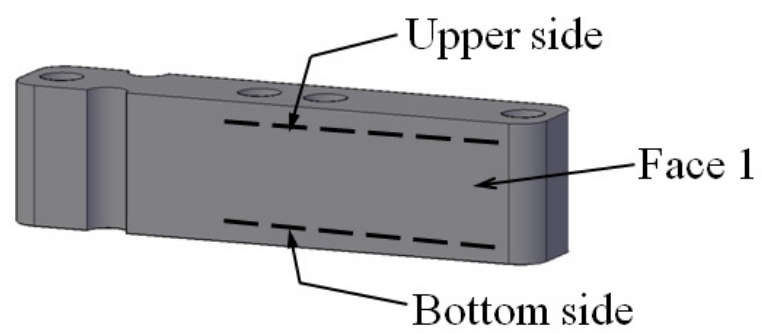

Fig. 3. Positions of the measurements on the sample part.

\section{Analysis of the results}

\subsection{Influence of the traverse speed on the surface roughness}

Figure 4 shows the variation of the surface roughness Ra depending on the traverse speed, for the upper side (Up) and the bottom one (Dw) and two values of the standoff distance (STD). The surface roughness increases with the increase of the traverse speed. This variation is in accordance with all other previous researches done by others [5-10]. But the intensity of variation is different. On the upper side of the part (Up), where the abrasive jet enters into the material, the surface roughness slightly changes with the increase of the traverse speed. There can be stated that at small thickness values, under $5 \mathrm{~mm}$, the traverse speed practically does not influence the surface quality of the parts. In Figure 5 there can be seen some parts which visually confirm the statements made here. The upper left part was nr.2 of the trial (see Table 3 ) and the down left one was nr.3.

On the bottom side of the part (Dw), where the abrasive jet exits the material, the traverse speed has a significant influence on the surface roughness. This can be explained 
by the bending effect of the jet which intensifies with the increase of the traverse speed [6, 7]. At lower traverse speeds, under $45 \mathrm{~mm} / \mathrm{min}$ the increase of the roughness is small, but at higher speeds the increase is significant and the quality of the part becomes unacceptable due to visible ridges which can be seen on the surface (Figure 5).

Based on the results the adequate value of the traverse speed to be used for $20 \mathrm{~mm}$ thick Hardox should be below $45 \mathrm{~mm} / \mathrm{min}$. This can be obtained on an Omax type machine by using a combination of the machinability number 60 and the quality number over 2 .

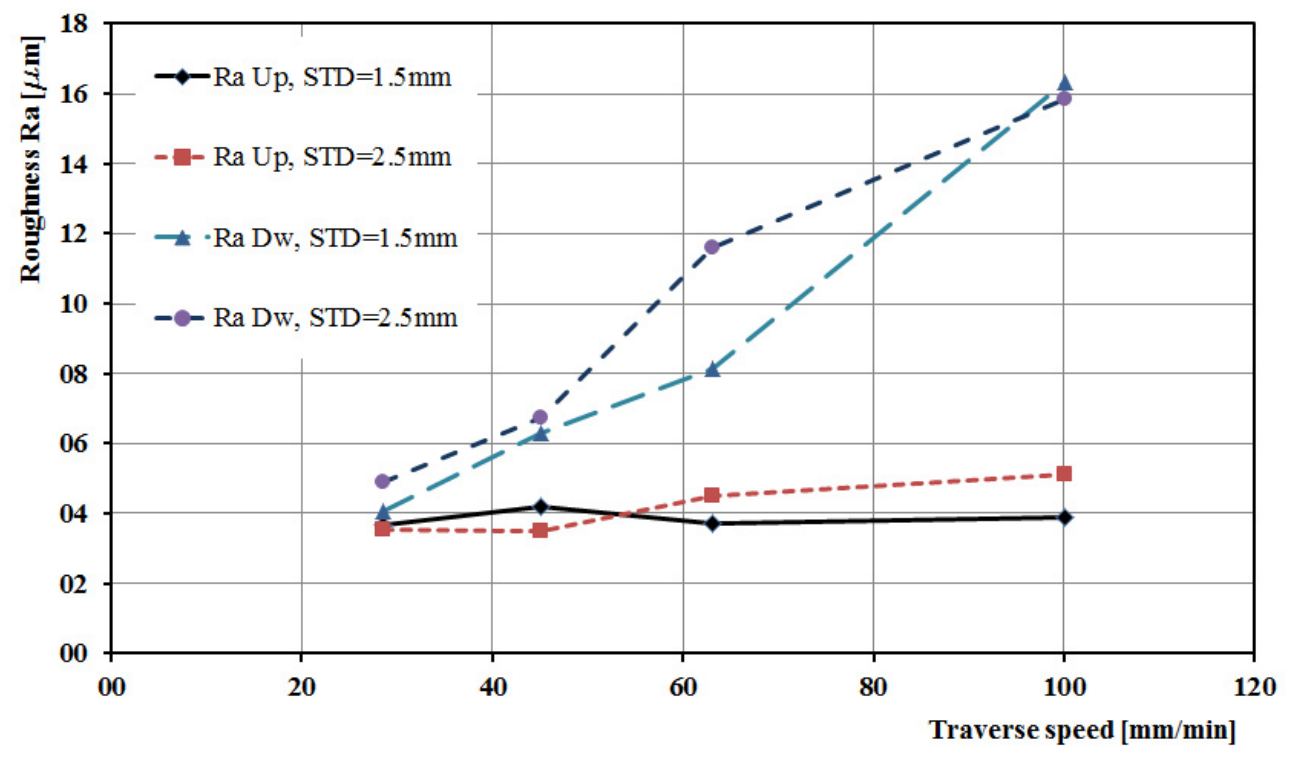

Fig. 4. The variation of surface roughness Ra with the traverse speed (TRS).

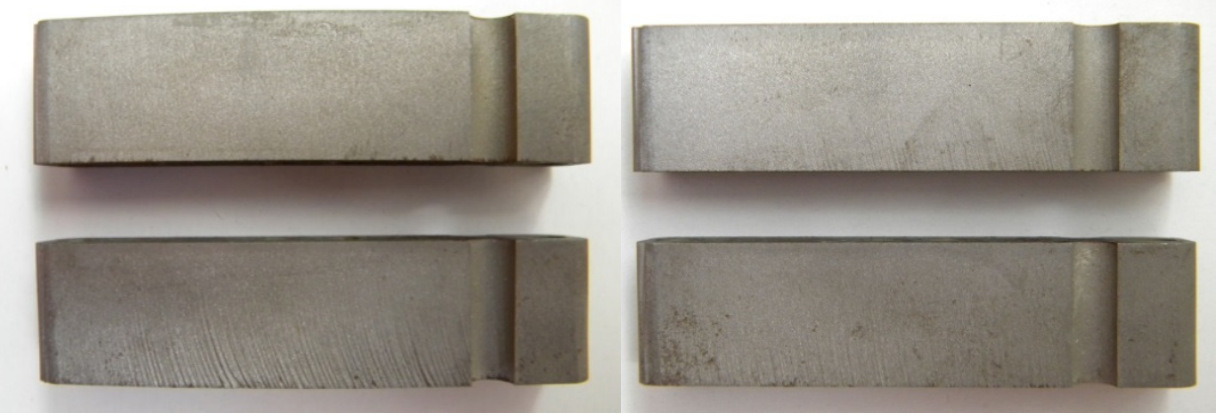

Fig. 5. Samples of parts manufactured during the trials.

Up Left - TRS $=28.48 \mathrm{~mm} / \mathrm{min}$, Down Left - TRS $=100 \mathrm{~mm} / \mathrm{min}$.

Up Right - TRS $=63.18 \mathrm{~mm} / \mathrm{min}$, Down Right - TRS $=45.07 \mathrm{~mm} / \mathrm{min}$.

\subsection{Influence of the standoff distance on the surface roughness}

The variation of the surface roughness depending on the standoff distance (STD) is shown in Figure 6. As seen in the diagrams, the standoff distance has a different influence on the roughness, depending on the position of the surface along the thickness of the part. Generally, the increase of STD leads to a slight increase of the surface roughness. If the standard deviation is calculated for the two sides of the part which were analyzed, the 
values are 0.6 for the upper side of the part (Up) and 4.8 for the bottom one (Dw). Therefore, it can be stated that the standoff distance has a more significant influence on the bottom side of the part which is the exit side of the abrasive jet.

Based on the results the recommended value of the standoff distance can be suggested in the interval $1.5 \ldots 2.0 \mathrm{~mm}$.
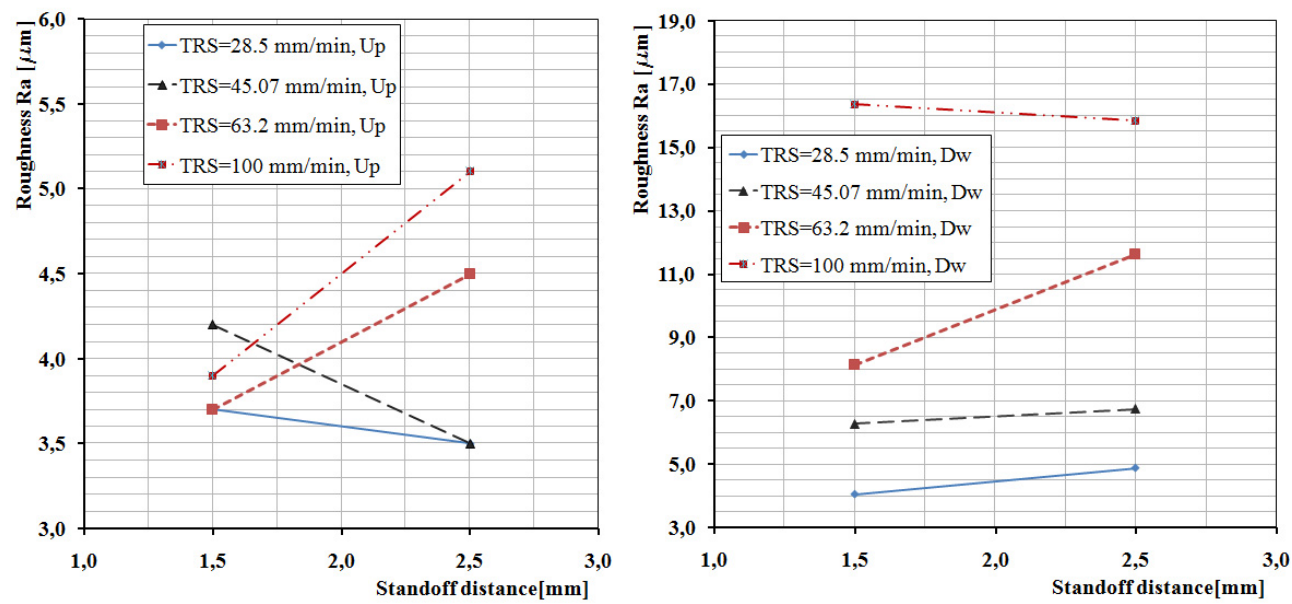

Fig. 6. The variation of surface roughness Ra with the standoff distance (STD).

\subsection{Influence of the process parameters on the dimensional accuracy}

The dimensional accuracy was analyzed by measuring the width of the parts, in the middle of its length, on the two faces both on the upper and the bottom sides of the part, Figure 3. The nominal value of the width was $15 \mathrm{~mm}$ (Figure 2a). The diagrams in Figure 7 show the variation of the mean values for the part's width on the variable process parameters considered in the experiments, the traverse speed TRS and the standoff distance STD.

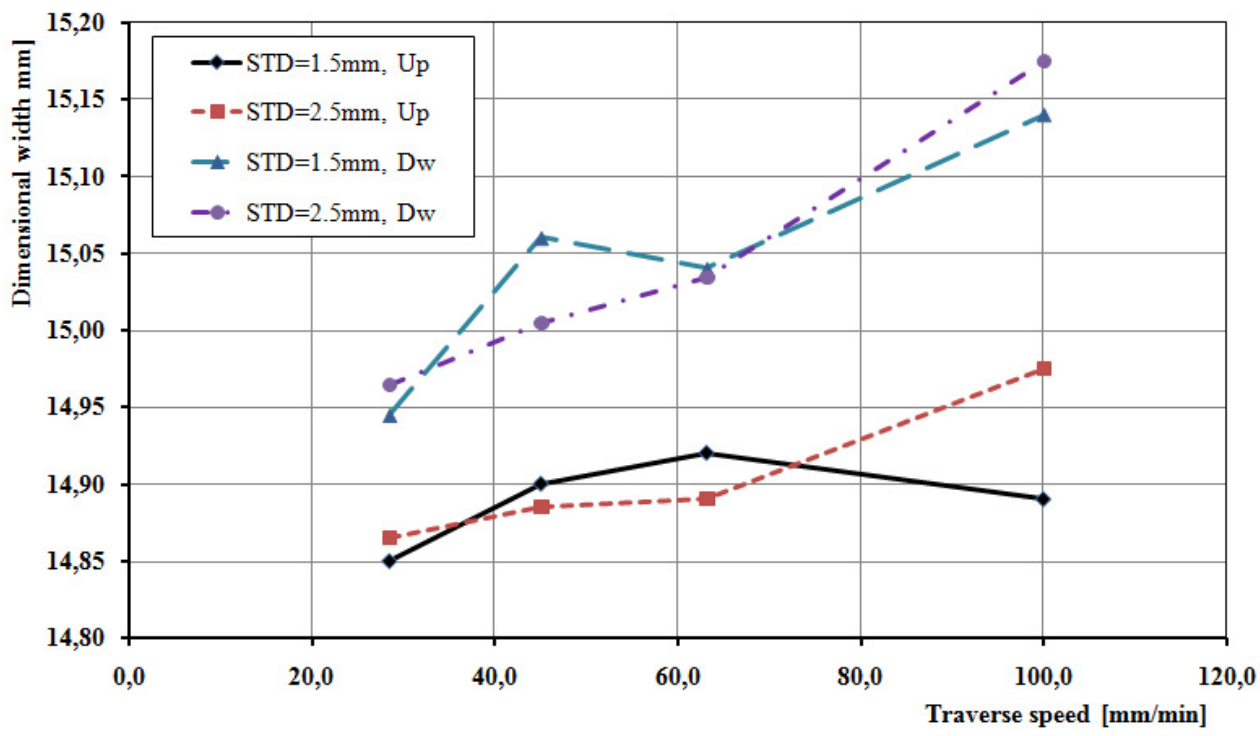

Fig. 7. The variation of the width of the parts on the process parameters. 
According to the diagrams shown in Figure 7 the variation of the dimensional accuracy on the process parameters is similar to that of the surface roughness (see Figure 4). On the upper side of the part, at the entrance of the abrasive jet the increase of the dimension with the increase of the traverse speed is slightly smaller than the one found on the bottom side of the part.

Because the equipment used for experiments is not provided with automatic taper effect compensation, the dimension on the upper side of the part is smaller than the one of the bottom side. The difference is between 0.10 and $0.25 \mathrm{~mm}$. For the adequate value of the traverse speed below $45 \mathrm{~mm} / \mathrm{min}$, stated in chp.3.1, the difference is below $0.14 \mathrm{~mm}$, so it can be stated that the precision of the process is around this value.

The standoff distance seems to have a small influence on the dimensional accuracy of parts. The influence is slightly higher when the traverse speed has bigger values. The differences are below $0.1 \mathrm{~mm}$, so it can be stated that the standoff distance has a very small influence on the dimensional precision of parts.

\section{Conclusions}

Abrasive waterjet cutting can be successfully used for manufacturing steels with a hard strength like Hardox [2]. The research of this paper proves this fact without any doubt.

Like all previous researches have demonstrated [4-5, 8-10], the main process parameters which affect the quality of the parts are the jet pressure, the traverse speed and the abrasive flow rate. Because the jet pressure is recommended to be used at the maximum value provided by the equipment for productivity reasons this parameters was kept constant. Because the equipment used in experiments does not have the possibility to consistently vary the abrasive flow rate, this parameter was also kept constant during the tests. The research of this paper revealed the influence of the traverse speed. It was also analysed the influence of the standoff distance even if it is not a major influence parameter.

The quality of the parts was assessed by measuring their dimensions and surface roughness.

The main conclusions of the research are:

- The traverse speed strongly influences the quality of the parts, as shown in Figs.4 and 7. If the speed is over a certain limit, the surface become extensively ridged and will be unacceptable. For Hardox 400, the type of steel used, this limit is considered around 45 $\mathrm{mm} / \mathrm{min}$. for parts having the thickness around $20 \mathrm{~mm}$.

- The standoff distance has a small influence on the quality of the parts, as shown in Figure 6. Based on the results of tests, it can be stated that the adequate value of the standoff distance should be in the range $1.5 \ldots 2.0 \mathrm{~mm}$.

- The analysis of the cutting time (Table 3) show that the increase of traverse speed proportionally leads to a shorter time, but the quality of parts becomes worse. Usually, at AWJ a compromise has to be made between these two parameters to ensure the required quality in the smallest time possible.

Further research will be developed for different other values of the material thickness to establish a mathematical model for choosing the correct value of the machinability number in the case of Hardox 400 alloy steel when it is manufactured by abrasive waterjet cutting (AWJ).

The experiments realized in the present research were made with the support of the project PN-III-P22.1-BG-2016-0206, ProWaterjetTech, financed by UEFISCDI, using also the infrastructure of the "Metrology Lab Mitutoyo" from the "Institute High Tech Products for Sustainable Development: PRO-DD", lab created with the contribution of Mitutoyo Romania S.R.L. 


\section{References}

1. H. Bugłacki, M. Smajdor, Mechanical properties of abrasion-resistant Hardox 400 steel and their welded joints, Adv. In Mat. Science 4, 2 (2003)

2. Hardox steels. http://www.ssab.com/products/brands/hardox. Accessed March 2016.

3. A.W.Momber, R.Kovacevic, Principles of Abrasive Waterjet Machiningm (Springer London Limited ,1998)

4. A.C.Filip, H.Bulea, Surface precision on the circular abrasive waterjet machining of ceramic aluminium oxides, MTeM'2013, 8 (2013)

5. M. Hashish, A model for abrasive - waterjet (AWJ) machining, J. Eng. Mater. Technol. Transactions of the Asme 111 (1989)

6. L.Hlavac, Theoretical model of abrasive liquid jet, Transactions of the VSB 47, 73 (2001)

7. W. Li, J. Wang, H. Zhu, H. Li, C. Huang, On ultrahigh velocity micro-particle impact on steels-a single impact study, Wear 305, 216 (2013)

8. J. Folkes, Waterjet- An innovative tool for manufacturing, J.Mater.Process.Tech. 209 6181 (2009)

9. H. Li, J. Wang, An experimental study of abrasive waterjet machining of Ti-6Al-4V, Int. J. Adv. Manuf. Technol. 81, 361 (2015)

10. D. Begic-Hajdarevic, A. Cekic, M. Mehmedovic, A. Djelmic, Experimental Study on Surface Roughness in Abrasive Water Jet Cutting, Procedia Engineering, 100 (2015) 